\title{
INDAGAÇÕES NA/COM A EJA NO CONTEXTO DE PANDEMIA: UMA EXPERIÊNCIA EM CÍRCULOS DE CULTURA DIGITAIS
}

\author{
INQUIRIES IN / WITH EJA IN THE CONTEXT OF THE PANDEMIC: AN EXPERIENCE \\ OF A DIGITAL CULTURAL CIRCLE
}

\author{
INDAGACIÓNES EN / CON EJA EN EL CONTEXTO DE PANDEMIA: UNA \\ EXPERIENCIA DE UN CÍRCULO DE CULTURA DIGITAL
}

\author{
Soraia Sales Baptista da Costa Machado \\ Secretaria Municipal de Educação de Salvador - Brasil \\ Universidade de Coimbra - Portugal \\ Graça dos Santos Costa \\ Universidade do Estado da Bahia -Brasil \\ Universidade de Barcelona-Espanha \\ David Mallows
UCL Institute of Education - Reino Unido \\ Patrícia Lessa Santos Costa \\ Universidade do Estado da Bahia - Brasil
}

\begin{abstract}
Resumo: Neste artigo, usamos a metodologia freireana dos Círculos de Cultura para explorar o desenvolvimento profissional contínuo dentro de uma Comunidade de Práticas em Educação de Jovens e Adultos (EJA) no Brasil em tempos de pandemia. Começamos por afirmar a importância da EJA no enfrentamento da exclusão imposta há décadas a parcelas da população no que se refere aos benefícios da educação. Conceituamos quem trabalha na EJA como uma comunidade de práticas e refletimos sobre o papel central da UNEB/MPEJA na formação dessa comunidade. Em seguida, apresentamos o projeto Indagações na / com a EJA em Tempos de Pandemia, realizado com uso das tecnologias da informação e comunicação, cujo objetivo principal foi interrogar, refletir e analisar os desafios e possibilidades das políticas públicas para a EJA no contexto da pandemia, por meio de um processo dialógico e democrático, possibilitando àqueles que se comprometem com a EJA em compartilhar e refletir sobre suas práticas. Sugerimos que o fortalecimento da Comunidade de Práticas em Educação de Jovens e Adultos (EJA) pode promover a inovação, desenvolver capital social e facilitar a criação e disseminação de conhecimento sobre, na e para a EJA na Bahia.
\end{abstract}

Palavras chave: Círculos de cultura. Comunidade de práticas. Educação de jovens e adultos. 


\begin{abstract}
In this article we use the methodology of the Freirian Culture Circle to explore continuing professional development within a Community of Practice in youth and adult education (EJA) in Brazil in times of pandemic. We begin by affirming the importance of EJA in tackling the exclusion imposed for decades on portions of the population with regard to the benefits of education. We conceptualize those working in EJA as a community of practice, and reflect on the central role of the UNEB MPEJA in nurturing that community. We go on to present the project Inquiries in / with EJA in Times of Pandemic whose main purpose was to interrogate, reflect and analyze the challenges and possibilities of public policies for EJA in the context of the pandemic, through a dialogical and democratic process, enabling those who are committed to EJA to share and reflect on their practices. We suggest that strengthening the Community of Practice in youth and adult education (EJA) can promote innovation, develop social capital, and facilitate the creation and dissemination of knowledge about, in and for EJA in Bahia.
\end{abstract}

Keywords: Community of practice. Cultural circles. Youth and adult education.

Resumen: En este artículo utilizamos la metodología del Círculo de Cultura Freiriana para explorar el desarrollo profesional continuo dentro de una Comunidad de Práctica en Educación de personas Jóvenes y Adultas (EJA) en Brasil en tiempos de pandemia. Comenzamos afirmando la importancia de la EJA para abordar la exclusión impuesta durante décadas a sectores de la población con respecto a los beneficios de la educación. Conceptualizamos a quienes trabajan en EJA como una comunidad de práctica, y reflexionamos sobre el papel central de la UNEB/MPEJA en nutrir dicha comunidad. Continuamos con la presentación del proyecto indagaciones con la EJA en Tiempos de Pandemia cuyo objetivo principal fue interrogar, reflexionar y analizar los desafíos y posibilidades de las políticas públicas para la EJA en el contexto de la pandemia, a través de un proceso dialógico y democrático, posibilitando a aquellos que están comprometidos con EJA a compartir y reflexionar sobre sus prácticas. Sugerimos que el fortalecimiento de la Comunidad de Práctica en EJA puede promover la innovación, desarrollar el capital social y facilitar la creación y difusión de conocimiento sobre, en y para EJA en Bahía.

Palabras clave: Círculo cultural. Comunidad de práctica. Educacion de jóvenes y adultos.

\title{
Notas introdutórias
}

Neste artigo, enfocamos a Educação de Jovens e Adultos (EJA) no Brasil em tempos de pandemia e o papel das comunidades de práticas, não somente como um assunto atual, mas, sobretudo, como uma realidade problematizada na perspectiva freireana. Intentamos trazer a relação entre a universidade e a EJA, no sentido do desenvolvimento da formação dos sujeitos atuantes nesse campo da educação, por meio de um processo de articulação de esforços interligados numa visão de aprendizagem mútua e compromisso no/com o mundo, no enfrentamento da exclusão imposta durante décadas a parcelas da população no que tange aos benefícios da educação.

Apesar da educação no Brasil ser consagrada como direito de todos e dever do Estado, esta é, frequentemente, negada em um país no qual a desigualdade social e econômica se expressa de forma multifacetada, como nas diferenças de oportunidades de acesso a uma educação escolarizada de qualidade. Isso gera, dentre outros fatores, evasão escolar em larga 
escala e, consequentemente, produz sujeitos à margem das possibilidades de ingresso mais qualificado no mercado de trabalho proporcionado pelas credenciais educacionais.

No sentido atribuído por Heller (1985), a educação é uma necessidade presente em toda a sociedade e faz parte das demandas individuais. Enquanto necessidade, ela é expressa na forma de desejo (sentido do indivíduo) ou carência (sentido coletivo). Enquanto os desejos pertencem à esfera psicológica e emocional, as carências expressam uma necessidade coletiva demandada ao Estado como agente responsável pelo seu provimento. A educação, e aqui mais de perto falando sobre a Educação de Jovens e Adultos, pode ser então entendida na esfera dos desejos e das carências, com alto valor atribuído pelos indivíduos e pelas sociedades, configurando-se como necessidade sociopolítica de primeira instância.

A EJA oferece a esses adultos oportunidades para a melhoria da vida, mas, para que isso ocorra, os adultos precisam ter acesso à educação de qualidade, não apenas para compensar a falta de certificados escolares, pois a conclusão de sua escolaridade formal não garante que esse adulto tenha o conhecimento e as habilidades necessárias para prosperar em nossas sociedades modernas e complexas. Esse é, particularmente, o caso quando os adultos estão trabalhando em empregos que exigem pouco do conhecimento ou das habilidades formais que aprenderam na escola. Se eles não são obrigados, por exemplo, a ler e escrever muito em sua vida profissional, ou a fazer cálculos, é provável que essas habilidades diminuam com o tempo, com o risco de criar uma subclasse grande, economicamente vulnerável e que depende de outros para interpretação e acesso à informação (GROTLUESCHEN et al, 2016).

O círculo vicioso de subutilização e consequente perda de habilidades é um lembrete de que a educação de adultos não pode ser vista como uma compensação, mas como uma reparação, na perspectiva do direito negado, retomando o compromisso de possibilitar aos adultos das classes populares uma vida melhor e adaptarem-se aos desafios e mudanças ao longo dela.

A EJA é uma arena capaz de inserir os sujeitos nas oportunidades de vida, abarca processos diversos que incluem qualificação profissional, formação política e cultural, formação de identidades e reconhecimento social que fomenta um sentido positivo dos sujeitos. Tratam-se, pois, de processos de aprendizagem capazes de inserir os sujeitos no mundo, como atores dinâmicos, produtores de ações e demandas que fortalecem vínculos sociais.

No entanto, diante do enorme desafio de mitigar o impacto do fracasso do sistema escolar formal e apoiar os jovens e adultos a navegarem em um mundo em rápida mudança, a Educação de Jovens e Adultos no Brasil é campo em disputa, no qual há falta de identidade clara e compartilhada, bem como carência de visibilidade dentro do sistema educacional. 
Neste ponto, destacamos o papel da universidade e seus laços com a educação básica, mediatizados pela formação institucionalizada (graduação e pós-graduação), assim como por meio de projetos de extensão, que fomentam capital social necessário à melhoria da qualidade da educação. Nesse aspecto, a abordagem de Bourdieu (1998) sobre capital social numa perspectiva microssocial, no âmbito das interações entre indivíduos, é relevante. O autor considera que indivíduos e grupos são portadores de vários tipos de recursos sociais, como o capital econômico, simbólico, cultural, histórico. O social é visto por ele como um conjunto de recursos que estão ligados à posse de uma "rede durável de relações mais ou menos institucionalizadas", em que os agentes se reconhecem como vinculados a um determinado grupo, unidos por ligações significativas. A filiação a grupos ou instituições pode ser explicada pelos recursos que o capital social pode gerar para seus membros - valores compartidos, relações sociais, status social conquistado, trocas e reciprocidade.

Nesse ponto, a reprodução desse tipo de capital social depende de instituições - como universidades e rede de educação básica - que favoreçam as trocas e também o

[...] trabalho de sociabilidade, série contínua de trocas onde se afirma e reafirma incessantemente o reconhecimento e que supõe, além de uma competência específica e de uma disposição adquirida para obter e manter essa competência, um dispêndio constante de tempo e esforços, e também, muito frequentemente, de capital econômico. (BOURDIEU, 1998, p. 68).

Para Bourdieu(1988), o capital social é um conjunto de recursos que resulta do fato de o indivíduo pertencer a uma rede de relações de interconhecimento. Nesse sentido, o conceito se aproxima do nosso entendimento das comunidades de práticas, no campo da Educação de Jovens e Adultos, no sentido de que estas fomentam o capital social.

A Pandemia da COVID-19 lançou uma luz dura sobre as desigualdades já existentes em nossas sociedades e também sobre as possibilidades de ação dentro deste campo. Para a EJA, a pandemia ampliou a invisibilidade e a falta de conexão dos membros mais importantes de qualquer sistema educacional: os professores. $\mathrm{Na}$ EJA, os professores costumam trabalhar em isolamento, sem acesso ao desenvolvimento profissional. Neste contexto, um grupo de docentes da universidade e da educação básica (dez egressos do Programa de Pós-Graduação em Educação de Jovens e Adultos) adotou a proposta freireana do Círculo de Cultura, realizando encontros por um período de quatro meses entre abril e julho de 2020 para fomentar diálogos com egressos de todas as turmas do Programa sobre os temas do currículo, gestão, pesquisa, privação de liberdade na EJA, assim como a formação profissional continuada dentro da Comunidade de Práticas da EJA. O processo dialógico e democrático possibilitou àqueles que 
estão comprometidos com a EJA, o compartilhamento e reflexão sobre suas práticas, como será discutido neste artigo.

\section{A Comunidade de Práticas da EJA na Bahia}

Em tempo de pandemia, a necessidade de formar conexões entre as pessoas que trabalham na EJA ficou ainda mais urgente. Uma forma de falar sobre esses professores e gestores - de pensar neles como um grupo com interesses e experiências em comum - foi fazer uso da dinâmica da comunidade de práticas (LAVE; WENGER, 1991). Uma comunidade de práticas é constituída por profissionais que estão equipados com procedimentos compartilhados para falar e agir em um contexto social particular. Nesse caso, o contexto social é a escola da EJA.

De acordo com Cabelleira (2007), o conceito de comunidade de práticas é muito útil para se refletir à construção do capital social, antes referido, pois se refere a relações permeadas pela adesão voluntária, horizontal, de autogestão, com informações que circulam horizontalmente, tecendo redes de confiança que permitem obter grande sucesso.

Tratando especificamente das comunidades de práticas no campo da educação, Wenger et al (2002) as diferenciam de outros tipos de associações - como grupos de trabalho ou redes informais ou equipes de projeto - por suas características: o objetivo, que é desenvolver as competências dos participantes, gerar e trocar conhecimentos; os participantes, que têm em comum a paixão, o compromisso e a identificação com os conhecimentos do grupo; o prazo, pois, tem prazo indeterminado já que dependem do interesse do grupo. Em suma, para Wenger (1998), as comunidades reúnem pessoas unidas informalmente - com responsabilidades no processo - por interesses comuns no aprendizado e na aplicação prática do aprendido. O termo tem como ponto forte o modo de associação focado no trabalho em conjunto, para resolver problemas de forma criativa, com habilidade advinda muitas vezes da experiência, para inventar melhores formas de lidar com os desafios. Destaca a importância dos conteúdos, dos aprendizados via experiência e processos de negociação e renegociação, as habilidades e os saberes individuais que fazem os sujeitos se sentirem pertencentes ao grupo (WENGER, 1998).

Importante evidenciar três elementos das comunidades de práticas: o domínio do conhecimento, pelo qual as pessoas se organizam, no caso em foco tratamos da EJA; a própria comunidade, pois as pessoas se relacionam estabelecendo laços de confiança, engajamento, que tecem redes de malha fina e proporcionam fortemente uma identidade; e a própria prática, considerando que as pessoas se capacitam na sua prática de desenvolvimento de um repertório e pelo compartilhamento de recursos - tais como ferramentas, documentos, rotinas, 
vocabulários, símbolos e artefatos - que incorporam o conhecimento acumulado pela comunidade. Esse repertório fundamenta futuras aprendizagens (WENGER, 1998).

Aprender a ensinar pode ser conceituado como aprender a participar do discurso e das práticas da comunidade de professores. Tal conceitualização da aprendizagem sugere que é possível uma pessoa gradualmente tornar-se capaz de dominar esses procedimentos, bem como as ferramentas semióticas e tecnológicas da comunidade, através da participação nessa comunidade em particular.

Para os formandos/ participantes/ integrantes construírem suas próprias ideias de ensino e aprendizagem, eles devem estar imersos em uma comunidade de discurso que os incentive a serem aprendizes, para que "a experiência possa ser dissecada, avaliada e refletida para que princípios de pedagogia e ação sejam construídos (FOSNOT,1989, p. 20).

A comunidade de práticas da EJA na Bahia já existe. Contudo, ainda se apresenta frágil e desconectada. Investir na comunidade de práticas da EJA na Bahia quer dizer investir na conectividade das pessoas implicadas com a EJA na Bahia; quer dizer facilitar a troca de experiências para ajudar a reflexão e a formação desse grupo de pessoas. E isso nunca foi tão importante quanto agora, em tempo de pandemia. Por outro lado, fortalecer a comunidade de práticas da EJA na Bahia poderá promover a inovação, desenvolver o capital social e facilitar a criação e disseminação do conhecimento sobre, na e para a EJA na Bahia. Isto precisará ser um percurso construído numa proposição dialógica, contextualizada, numa vivência de aprendizagem coletiva e horizontalizada, sustentada na contínua ação e reflexão, a partir das indagações desta realidade problematizada. E esta não é uma criação nova, mas a reinvenção da proposta freireana, num contexto de isolamento social, preponderantemente, virtual/remoto.

\section{Os Círculos de Cultura na/com a EJA}

Desde a sua gestação, no solo do nordeste brasileiro, os Círculos de Cultura foram forjados a partir da problematização da realidade. Na perspectiva freireana, a realidade, que é histórica, constitui-se numa criação humana. Estar no mundo enquanto ser histórico diferencia os seres humanos dos outros animais, que, de forma a-histórica, não se relacionam com o mundo, somente estão em contato, pois nele estão imersos num eterno presente, sem a consciência da sua própria presença (FREIRE, 1983).

A singularidade humana se revela na capacidade de se distanciar do mundo para admirálo. A "ad-miração", ao realizar este afastamento, aproxima-o mais da realidade, a fim de melhor analisá-la, compreendê-la e, principalmente, nela intervir de forma consciente. Os mesmos que têm a possibilidade da criação, também são capazes de transformá-la, assim, constituindo-se 
em seres comprometidos na relação com o mundo, através do agir e refletir (FREIRE, 1983). "A prática consciente dos seres humanos, envolvendo reflexão, intencionalidade, temporalidade e transcendência, é diferente dos meros contatos dos animais com o mundo" (FREIRE, 2011, p.108).

$\mathrm{O}$ direito à educação, vilipendiado historicamente quando direcionado à classe popular no Brasil, resultou em um alto índice de analfabetismo, evidenciado nos anos de 1960 (consequência ainda presente na atualidade), o que significou para os participantes desta ação cultural uma legítima convocação. A Educação de Jovens e Adultos, situada na Educação Popular, como enfatizou o próprio Paulo Freire (2008), aparece então como contexto originário da metodologia, segmento no qual os educandos trazem marcas da exclusão nos mais diversos aspectos, como educacional, social, econômico, dentre outros.

$\mathrm{Na}$ proposição de um percurso teórico reflexivo, mais que respostas argumentativas ou conclusivas, as indagações podem ser colocadas como provocações desencadeadoras de aprendizagens significativas e mudanças:

- Nesse contexto pandêmico, os Círculos de Cultura corresponderiam a uma possibilidade de intervenção educativa comprometida com a transformação nos mais diversos âmbitos, especialmente na EJA?

- Nas diferentes realidades, quais as possibilidades de reinventar os Círculos de Cultura?

- O diálogo é viável em tempos de pandemia, nos quais o isolamento se constitui em uma medida de sobrevivência?

Para não simplificar numa resposta conclusiva, uma caminhada através de dados históricos, como também a apresentação de alguns princípios e fundamentos, poderá contribuir nesta trilha investigativa e reflexiva a respeito dos Círculos de Cultura. Diferentemente de uma aula expositiva ou de um mero discurso, os quais se apresentariam incoerentes com a dialogicidade, cerne fundante desta metodologia, o que se intenta é uma discussão propositiva, pois a compreensão mais genuína e profunda ocorre ao vivenciá-la. Segundo ROMÃO (2011, p. 68), “a validade epistemológica e política dos 'Círculos de Cultura' só se constrói na aplicação desta metodologia já na compreensão do que é um Círculo de Cultura", sem prescindir dos fundamentos e princípios da pedagogia que o sustenta. Complementa advertindo que não faz sentido uma aula sobre Círculos, se estes são uma substituição das aulas (ROMÃO, 2011).

Faz-se, então, imprescindível abordar o entendimento de alguns de que os Círculos seriam um método. Esta é uma compreensão que o próprio Paulo Freire (MEKSENAS; PENTEADO, 1982). refutava, expressando-se incomodado em abordar o assunto, devido ao 
reducionismo presente na compreensão, ao aprisioná-los em um método abarrotado de técnicas. Ele declara, então, ser uma pedagogia, uma concepção de mundo, enfatizando a presença do ser humano no mundo, acompanhada na companhia do outro (MEKSENAS; PENTEADO, 1982). Da mesma forma, estudiosos das suas obras, pensamento, andarilhagens e práticas esclarecem seu olhar ampliado e crítico sobre a metodologia, como a sistematização e concretização da sua práxis (ROMÃO, 2011), uma "teoria de aprendizagem” (RODRIGUES, 2011 p. 22), "uma teoria crítica e emancipatória” (SILVA, 2014, p. 104), “uma educação contra outras" (BRANDÃO,1986, p. 15) e a favor dos oprimidos (ALCOFORADO, 2013), uma "ação cultural" projetada para a alfabetização de adultos a ser ampliada "para a educação como um todo" (SCOCUGLIA, 2001, p. 333). Mais uma vez, nas palavras de Brandão (1986), essa amplitude no olhar fica explícita ao descrever a experiência prática vivida:

[...] ali não se experimentava só um novo método, mas através dele, um novo sentimento de Mundo, uma nova esperança no Homem. Uma nova crença, também no v alor e no poder da Educação. Sinais de amor que o homem planta brotavam ali, no chão seco do sertão [...] (BRANDÃO,1986, p. 8).

$\mathrm{Na}$ sequência desta reflexão/deste estudo, outras indagações norteiam nossas preocupações: Qual a origem dos Círculos de Cultura? Por que e por quem foram criados? Quais seus princípios e fundamentos? Qual o contexto histórico no qual foram forjados? Sem a pretensão de uma abordagem aprofundada, dialogar com tais questionamentos pode contribuir para esta discussão.

Nascido num cenário de ebulição no Brasil dos anos de 1960, quando a América Latina, de um modo geral, apresentava movimentos em diferentes espaços na luta por direitos e por sociedades menos desiguais, a metodologia freireana comprometeu-se com o desafio de ultrapassar os limites do discurso à ação, da teoria à prática (GUERRA, 2013).

Os primeiros Círculos aconteceram em zonas populares do Recife, em diversos espaços cedidos pelas comunidades, assim como a divulgação acontecia por meio de recursos populares (FREIRE, 2015). A ampliação aconteceu para as cidades de Angicos e Mossoró, no Rio Grande do Norte, e em João Pessoa, na Paraíba: a pedagogia popular e revolucionária gestada estava em movimento de expansão. No Rio de Janeiro, São Paulo e em Brasília, outros Círculos foram vivenciados (BRANDÃO,1986).

Os resultados alcançados, com 300 trabalhadores alfabetizados em 45 dias, impulsionaram o governo federal a estender sua aplicação em todo o território nacional, construindo um plano de ação com o objetivo de realizar 20.000 Círculos de Cultura para a formação de dois milhões de educandos em um ano (FREIRE, 2016). Entretanto, o golpe militar 
de 1964 interrompeu a utopia possível que se despontava para o povo brasileiro. A proposição da pedagogia freireana, sustentada em princípios e fundamentos de libertação e emancipação, pautada no processo de conscientização, foi censurada, e o seu criador foi banido do país, num exílio que durou 16 anos. Ao tempo em que sua terra natal foi privada dos benefícios de uma educação revolucionária, em outras partes do planeta sua passagem deixou marcas significativas da sua práxis (ROMÃO, 2011). Tal medida repressiva, contraditoriamente, resultou na expansão do pensamento freireano por todo o mundo, até os dias atuais.

Mais uma vez, na perspectiva problematizadora, cabe a indagação de Romão (2011), referida àquele contexto, como na contemporaneidade: "Por que o 'Método Paulo Freire' era tão ameaçador para as elites brasileiras? O que ele continha de tão subversivo [...]?" (ROMÃO, 2011, p. 62). Instigações que se desdobram em outras questões a serem investigadas e refletidas neste estudo: Quais são estes “ameaçadores" princípios e fundamentos que norteiam esta metodologia? Que práticas estão propostas nesta prática/metodologia tão revolucionária? Para que, por que, para quem propor a vivência dos Círculos de Cultura?

No entendimento de que cultura é o acrescentamento do homem ao mundo, sua ação criadora e transformadora nele, a metodologia identificada como Círculos de Cultura não apenas expressa uma perspectiva mais ampliada da prática pedagógica, como também uma explicitação dessa intervenção enquanto sujeito no mundo e não de mero objeto (FREIRE, 1983). É uma expansão do olhar, da percepção de si, do outro, do mundo, como "sujeito da criação cultural" (ROMÃO, 2011, p. 69), a qual se faz coletiva na construção do conhecimento.

A opção pelo vocábulo cultura, dentre possibilidades como escolar, educativo ou pedagógico, além da amplitude, traz, concomitantemente, a transcendência da compreensão de educação e a associação permanente a ela. Escolha coerente a uma proposição que objetiva a superação da "consciência ingênua" para a consciência crítica (PADILHA, 2012), na recriação da realidade à medida que vai compreendendo-a mais criticamente, fissurando-a para sua apreensão e transformação, na transposição da doxa para o $\operatorname{logos}$, na construção do conhecimento crítico (LOUREIRO; FRANCO, 2014).

A cultura é entendida nos Círculos, enquanto processo de humanização, na perspectiva ontológica e gnosiológica, como uma aquisição sistemática da experiência humana, em uma incorporação crítica e criadora.Assim, os círculos negam a possibilidade de uma introjeção de informes e prescrições doados na vivência do ato educativo, não cabendo "dar aulas" e nem recebê-las como doação.

Como sujeitos, educandos e educadores são instigados a criar e recriar uma relação de interação, numa dimensão democrática da vivência e espaço educativo neste processo singular 
de humanização que caracteriza e distingue os seres humanos. Para tanto, não se poderá prescindir da ressignificação, da reinvenção dos papéis de educador e educando na legítima vivência dos Círculos. De forma reinventiva e transgressora, nos Círculos de Cultura, atuam como forjadores de cultura, em seu processo de conscientização, numa vivência problematizada e dialógica, na superação da cultura hegemônica, no reconhecimento das variadas culturas, validadas em suas especificidades, singularidades, em suas diferentes origens e histórias geradoras.

Desde sua origem e, mesmo nos dias atuais, apresenta-se como uma proposição desafiadora, uma necessária mudança difícil, mas possível (FREIRE, 2013), na qual o diálogo se faz presente em toda a sua concepção e vivência, em substituição ao silenciamento imposto na relação autoritária vivida no espaço escolar, ainda tão presente. É uma contraposição ao antidiálogo tão impregnado na formação e nas relações estabelecidas nos espaços educativos, especialmente, institucionalizados.

A dialogicidade é um eixo fundamental na metodologia freireana, articulada a outros dois, também basilares nesta proposição que são a problematização e a horizontalidade dos saberes e nas relações de aprendizagem vividas neste contexto educativo. Estruturas que representam um contraponto à educação bancária, na qual a verticalidade dos discursos se faz presente. Como explicita Freire (2014), sem a superação da contradição entre educadores e educandos, sem o rompimento da verticalidade, é impossível a realização de uma educação problematizadora como prática de liberd ade, assim como "também não lhe seria possível fazêlo fora do diálogo" (FREIRE, 2014, p. 95).

Segundo Loureiro e Franco (2014), uma prática pedagógica revolucionária, em diálogo permanente e amplo em sua concepção, não pode ser enclausurada nas amarras de um mero instrumento metodológico, mas reconhecida em seu potencial articulador de aprendizagens entrelaçadas. Por ser uma prática que se propõe libertadora está pautada no diálogo, na problematização, no reconhecimento do conhecimento enquanto construção coletiva, numa relação de comunhão horizontalizada de saberes na qual todos são sujeitos, e não objetos no processo de aprendizagem.

Seja em um breve percurso reflexivo, como este, ou em uma abordagem mais aprofundada, fica evidenciada "a inseparabilidade do ato político e do ato pedagógico/educativo" (SCOCUGLIA, 1999, p. 84) em todo pensamento, discurso e prática freireana. É um fio condutor que perpassa toda sua práxis, assumida e anunciada em sua não neutralidade, reivindicando do educador questionar-se: em favor de que, de quem, contra que, contra quem está o conhecimento? (FREIRE, 1982). São perguntas nas quais não cabe a 
neutralidade, mas a explicitação e escolha de uma educação a serviço da dominação ou a serviço da libertação de homens e mulheres (ALCOFORADO, 2016).

Torna-se fundamental, então, situar os Círculos no pensamento político pedagógico de Freire, presente ao longo da sua teoria, como também em sua prática, consequentemente na sua práxis, sustentada na indissociabilidade entre educação e política, na convicção da impossibilidade da neutralidade do ato educativo. A ação consciente das suas posições e finalidades faz-se fundamental, em resposta às ações de despolitização da educação que, como adverte Romão (2011), camuflam o poder hegemônico presente, que é essencialmente político, na tentativa de desarticular uma "ação pedagógica politicamente solidária aos interesses populares" (SCOCUGLIA, 2001, p.326).

Os Círculos de Cultura, assim como toda a proposição freireana, e qualquer outra que se consubstancie em uma educação democrática e libertadora, engajada na luta pela transformação de realidades injustas, trazem a assunção consciente do seu inegável caráter político.

Diante deste desafio da opção declarada e assumida em ações, encontram-se as instituições educativas, exercendo suas práticas, pesquisas e fazendo suas articulações, evidenciando sua posição político-pedagógica e os seus objetivos. Neste estudo, trazemos uma reflexão provocativa sobre o papel da universidade no apoio ao desenvolvimento de uma Comunidade de Práticas da EJA na Bahia. Em particular, focalizamos no Programa de PósGraduação em Educação de Jovens e Adultos do Mestrado Profissional (MPEJA) da Universidade do Estado da Bahia, e na relação estabelecida pelo MPEJA com seus egressos. Uma abordagem que intenta se articular reflexivamente nesta convicção e opção políticoeducativa.

\section{O Programa de Pós-Graduação em Educação de Jovens e Adultos (MPEJA) e o fomento às redes de interação dos seus egressos}

Neste ponto destacamos a experiência do Programa de Pós-Graduação em Educação de Jovens e Adultos do Mestrado Profissional (MPEJA) no sentido do processo formativo dos docentes da EJA na Bahia e Brasil, focado na sua profissionalização. Esse tema tangencia a discussão sobre o papel dos mestrados profissionais em educação para a prática docente. No caso específico, tomamos, como questão principal, o papel do Programa na formação dos docentes da EJA na Bahia e na possibilidade de contribuir para a consolidação da Comunidade de Práticas em EJA. 
O MPEJA é o único programa stricto sensu do Brasil sobre o tema, sendo criado por meio do Parecer Conselho Nacional de Educação/MEC 1009, de 11 de outubro de 2013. Desde 2013 desenvolve pesquisas voltadas para as seguintes Áreas de Concentração: 1 - Educação, Trabalho e Meio Ambiente; 2 - Formações de Professores e Políticas Públicas e 3 - Gestões Educacionais e Tecnologias da Informação e da Comunicação.

O papel dos mestrados profissionais tem sido amplamente discutido, no sentido da sua capacidade de fomento de pesquisa aplicada capaz de interferir no cotidiano da escola. Este é o caso do MPEJA, seja pela denúncia de realidades, seja pelo fomento de inovação, cultura política, redes de práticas, experimentação, dentre outros. Este é o ponto que nos conecta pensar a universidade e sua relação com a educação básica, e as comunidades de práticas. Estas, a nosso ver, podem trazer contribuições significativas ao trabalho pedagógico. Os temas defendidos no Programa MPEJA dão conta de uma variedade de problemas que são abordados em uma perspectiva teórica crítica, com densidade metodológica, bem como resultados práticos para o campo da EJA (suas escolas), viabilizados pelas metodologias participativas, como pesquisa-ação, pesquisa colaborativa, dentre outras.

O MPEJA na Bahia assume o desafio de formar profissionais em um campo formativo de frágeis empenhos acadêmicos, sociais e políticos. Por outro lado, representa a possibilidade de se construir e alicerçar um fértil campo de pesquisa e qualificação docente que possa preencher as lacunas formativas nesse campo de estudo. Nessa perspectiva, o MPEJA vem fomentando redes de práticas em todos os territórios da Bahia e, por meio de suas produções bibliográficas, eventos, cooperações institucionais internas e externas, pesquisas, programas e projetos, se configura como um elo articular dos profissionais da Educação de Jovens e Adultos. O Projeto Indagações, descrito a seguir, agregou egressos com experiência de 09 a 30 anos na EJA. A maioria tem experiência em gestão da educação e um membro tem experiência como gestora da Secretaria de Educação. Com base nos interesses comuns, os professores vêm se apoiando para pensar/agir sobre os desafios da EJA e pensar estratégias de resistências para o contexto atual.

Vale ressaltar que o Projeto Indagações colaborou para o adensamento das relações dos sujeitos da Comunidade de Práticas em EJA, como será discutido. Ademais, compreendemos que esta última não se restringe à soma de pessoas que passaram pelo processo formativo no MPEJA, mas é um grupo que se autogoverna e cujos membros compartilham interesses comuns, desafios, interagem e aprendem juntos. Os docentes são coparticipantes e negociam os conhecimentos que vão ser discutidos e trabalhos a serem desenvolvidos. 
O grupo tem como foco a experiência da prática e a gestão compartilhada do conhecimento. É um grupo heterogêneo de pessoas, com distintas experiências e níveis de formação, que compartilham interesse comum: a Educação de Jovens e Adultos.

Fruto de questionamentos contextuais sobre a EJA em tempos de pandemia e tendo ciência de que o "vírus que ameaça a EJA" não nasceu no contexto atual, mas é consequência do "fracasso" do sistema regular de ensino e das desigualdades sociais históricas da população vulnerável, 10 professores, apoiados pelo MPEJA, passaram a se reencontrar para compartilhar as vivências da EJA no contexto atual e relacioná-las às desigualdades sociais e desigualdades digitais.

O foco dos encontros era dialogar sobre as experiências, os problemas e as soluções (críticas e possibilidades) para trabalhar com Educação de Jovens e Adultos, mediada por Tecnologias da Informação e Comunicação (TIC). Nos encontros, eram partilhadas as vivências na/com a EJA no contexto da pandemia do COVID-19, explorando e investigando questões de interesses comuns das diferentes realidades, para avançar na ressignificação de aprendizagens, saberes, conhecimentos, fundados na reflexão conjunta e horizontal sobre a/na experiência da Educação de Jovens e Adultos na Bahia.

Os encontros permitiram que os professores gerassem conhecimentos pedagógicos por meio da reflexão crítica na prática, tendo um sentido formativo, orientado para inovação e melhoria do ensino entre iguais.

As reuniões da Comunidade apoiavam o desenvolvimento da competência de aprender a aprender, trazendo à tona a discussão sobre o que seria o conhecimento válido para a Educação de Jovens e Adultos, que metodologias seriam favoráveis para as diversidades de sujeitos e que sistemas de avaliação poderiam responder a tal complexidade.

As interações da Comunidade foram valiosas, por facilitarem as informações, percepções e orientações para resoluções de problemas. As indagações traziam à tona as situações, aspirações e necessidades e expectativas dos diferentes profissionais, favorecendo a exploração de ideias e ajuda mútua. O diálogo possibilitou uma aproximação a distintos contextos que apresentavam muitas semelhanças e pontos de divergências.

A Comunidade proporcionou uma relação mais íntima entre o grupo, abrindo espaço de afetos, de partilha de experiências e feedback entre os pares, por meio dos relatos das diversas ações que foram engendradas no grupo de forma flexível, respeitando as dinâmicas dos participantes. Os encontros não tinham estrutura hierárquica, pois todos os profissionais eram coparticipantes do processo de tomada de decisões. 
Na próxima seção, descrevemos um projeto idealizado e executado em parceria com este grupo de egressos da MPEJA (9 docentes da EJA e uma secretária acadêmica do MPEJA), seguindo esse espírito de questionamento e diálogo horizontal.

\section{Projeto Indagações na/com a EJA no contexto de pandemia: a experiência dos Círculos de Cultura digitais}

A realidade, quando problematizada, é instigadora e convoca os seres humanos ao compromisso com o seu tempo histórico. O Projeto Indagações na/com a EJA em Tempos de Pandemia, coordenado por dez atores da EJA na Bahia, com a participação de docentes da universidade, proporcionou a participação de egressos do MPEJA de todas as turmas, desde a primeira, ingressa em 2013, até a última, ingressa em 2019. Foi gestado, a partir das inquietações surgidas neste contexto desafiador, no qual, mais que respostas, seriam exigidas reflexões e ações retroalimentadas, capazes de gerir, como também transformar "situaçõeslimites". A EJA na Bahia representou um cenário de "provocações" transformadoras numa conjuntura que evidenciou situações já existentes e agregadas a outras que compõem esta modalidade na educação brasileira, já tão vilipendiada.

Dentro desta vivência de comunidade interativa, participativa e solidária, em comunhão de saberes e intencionalidade, constituem-se os Círculos de Cultura digitais da/com a EJA, sendo um espaço mediado pelas Tecnologias Digitais de Informação e Comunicação (TDIC), com o objetivo de promover lócus de escuta ativa, partilhas, problematização das diferentes saberes e experiências profissionais desta modalidade. Um fórum privilegiado de intercâmbio que busca fomentar o diálogo horizontal, o engajamento, a formação e a inovação pedagógica.

Assim, os Círculos de Cultura digitais tiveram por finalidade principal interrogar, refletir e analisar os desafios e possibilidades das políticas públicas para a EJA, com destaque no currículo, na formação docente e na gestão no contexto atual, buscando construir sínteses integradoras que representassem os diferentes sujeitos que atuam na EJA. Como objetivos específicos, o projeto propunha:

- Dialogar horizontalmente na/com a EJA em tempos de Pandemia, buscando levantar as diferentes situações vivenciadas por diferentes sujeitos desa modalidade, tendo em vista traçar estratégias coletivas para o enfrentamento do contexto atual;

- Problematizar e socializar práticas educativas vivenciadas por docentes da EJA, em tempos de pandemia, promovendo interlocuções entre diferentes coletivos que atuam na Educação de Jovens e Adultos e que estão vinculados ao MPEJA em seu processo formativo; 
- Interrogar, refletir e analisar os desafios e possibilidades das políticas públicas para a EJA, com destaque para a formação docente no contexto atual, buscando construir sínteses integradoras que representem os diferentes sujeitos que atuam na EJA.

Por meio de metodologia dialógica, foi tomado como ponto de partida o contexto social dos educadores da EJA, por meio de diálogo horizontal sobre as situações desafiadoras no contexto de pandemia. Com escuta às leituras de mundo e às experiências de educadores de vários territórios da Bahia, durante os meses de abril a julho, foram realizados seis encontros dialógicos. Foram realizados encontros de planejamento nos quais todos os coparticipantes contribuíram com revisão conceitual e metodológica.

Cada GT foi organizado por três mediadores da Comunidade de Práticas, os quais formularam questões geradoras para os encontros dialógicos e sistematizaram as distintas colaborações. As questões geradoras estavam em consonância com o campo de atuação/pesquisa de cada mediador e professores convidados.

Os grupos reuniam de 20 a 30 pessoas, egressas do MPEJA, muitas delas interrelacionadas, não somente neste momento, mas, fundamentalmente, na contínua luta pelo direito à educação de qualidade para todos e todas, especialmente, para os homens e mulheres da EJA. A cada debate nos Círculos de Cultura digitais, os grupos eram constituídos por egressos e estudantes do MPEJA que, em suas pesquisas e/ou atuações profissionais, estivessem envolvidos com as temáticas propostas.

Os egressos do Programa são professores das redes municipais e estaduais que estão presentes em todos os territórios baianos, cujas produções teórico-práticas visam a compreensão dos desafios que enfrentam e das possibilidades criativas, com vistas a proporcionar a melhoria da qualidade de ensino (criativo e crítico) dos jovens e adultos (DOS SANTOS COSTA et al, 2020)

A proposição de uma vivência de círculo dialógico virtual na perspectiva freireana corresponde a uma instigação de reinventar os Círculos de Cultura, neste caso, digital, e o isolamento social implicou a uma contingência a ser enfrentada e viabilizada no espaço virtual.

Os temas de discussão nos Círculos de Cultura digitais foram:

- G1: Formação de Professores na EJA;

- G2: Pesquisa na EJA;

- G3 e G4: Gestão na EJA (foram necessários dois encontros, pelo quantitativo de participantes e a necessidade de garantir um número em cada debate que verdadeiramente possibilitasse a fala e a escuta de todos);

- G5: Currículo da EJA; 
- G6: Privados de Liberdade e a garantia do direito à educação na pandemia.

A escuta ativa das vozes e o diálogo fecundo sobre as situações vivenciadas por diferentes profissionais da EJA possibilitaram uma inter-ação construtiva nos GT, nos quais foram tecidas estratégias coletivas para o enfrentamento do contexto atual.

O planejamento dos GT foi realizado pela autorregulação dos membros da Comunidade. Os membros modificaram a proposta, decidiram o grau de envolvimento e o tempo de dedicação ao projeto. Todos se implicaram na elaboração das bases do encontro: identificaram temas importantes; planejaram os encontros; sistematizaram as indagações; selecionaram os objetivos; estabeleceram, dialogicamente, a forma de trabalhar e conduzir o próprio diálogo.

Foi uma experiência rica, vivida no coletivo, norteada pela proposição freireana, na qual o diálogo possibilitou partilhas fecundas e acolhedoras para uma luta que não começou neste momento de pandemia do COVID-19, nem findará nele tampouco. O reconhecimento de pertencer a um coletivo de luta e o fortalecimento nela engajado, em uma comunhão amorosa, como tanto preconizou Paulo Freire(2013) implicou num compromisso comum e fortalecido nas próprias fragilidades de um campo de disputa, no qual, mais uma vez, "educadores sujeitos" se fizeram presentes.

\section{À guisa de conclusão}

Uma comunidade de práticas é um espaço de interação, intercâmbio e reflexão, no qual um grupo de profissionais que atuam no mesmo campo de conhecimento partilham saberes e experiências. É uma possibilidade de profissionalização e inovação que deve promover a colaboração e a cooperação entre docentes e a troca de saberes práticos profissionais. É uma das melhores alternativas para um modelo de formação docente, visando a criação de espaços de reflexão, formação e inovação pedagógica (BOZU; IMBERNON, 2009)

O sucesso em longo prazo de uma comunidade de práticas depende dos participantes da comunidade, por constituir-se em uma participação voluntária, pela necessária autodeterminação e relevância prática para os indivíduos e para a organização. Uma continuidade no âmbito da EJA se expressa e exige resistência e resiliência, pois não corresponde tão somente a um espaço de trabalho profissional, mas, sobretudo, a um campo de luta por direitos e pela assunção plena de cidadania ativa, uma convicção necessária aos que nela e com ela se comprometem.

No Projeto Indagações na/com a EJA em Tempos de Pandemia, sustentado numa comunicação fluida, baseada na relação de confiança e apoio mútuo, foi possível vivenciar experiências que corresponderam a significativas aprendizagens a serem socializadas, iniciadas 
pelos próprios integrantes, tais como: articulação e integração entre a atividade individual e o trabalho em rede e colaborativo; superação de barreiras de tempo, distância e outras situações desafiadoras geradas nesse contexto; dialogicidade crítica e reflexiva sobre realidades locais e regionais da EJA na Bahia, considerando suas (im)possibilidades de transformação; flexibilidade no processo formativo em uma construção contextualizada e coletiva, vivenciada de forma horizontalizada e interativa, diferentemente, de um programa pré-estabelecido com conteúdos a serem cumpridos e transmitidos na verticalidade, como em uma aula "doada" ou "depositada", dentre outras.

Tais aprendizagens provocativas impulsionaram ações no presente, como também constituíram-se em construção ou renovação de metas e estratégias aplicáveis às situações apresentadas, respondendo, inclusive, a necessidades surgidas no percurso do projeto, dentro da própria Comunidade, como, por exemplo, entender e acolher os desafios e possibilidades da EJA em tempo de pandemia, considerando seus sujeitos.

Os Círculos de Cultura digitais foram vividos com a clareza de que não se findarão no espaço de tempo no qual aconteceram, pois os encontros fecundos geram frutos que não são aprisionados em tempos e espaços rígidos. O mapeamento dos diferentes sujeitos e do espaço de atuação da EJA, tendo em vista ampliar a Comunidade de Práticas na EJA- Bahia, já se constitui em um deles, como também a possibilidade de produção de um livro sobre a EJA em tempo de pandemia; de artigos para revistas; da produção de vídeos sobre as narrativas de professores da EJA, abordando a Educação de Jovens e Adultos em contexto de pandemia, e de outros tantos que possam ser pensados e construídos na caminhada da Comunidade.

A partilha das ações e reflexões da Comunidade de Práticas deverá ser contínua na sua práxis, pois não há uma pretensão de discursos vazios, nem mesmo de práticas sem sustentação teórica, advertidos por Freire (2013) como uma impossibilidade de verdadeira transformação. O esperançar por ele anunciado, por não se restringir às denúncias, não se contenta com o esperar, mas com o agir em busca das "utopias possíveis" e dos "inéditos viáveis"; na consciência e concordância do que ele (FREIRE,2013) também "profetizou", de que as mudanças são tão difíceis quanto possíveis.

\section{REFERÊNCIAS}

ALCOFORADO, Luís. O que podemos aprender com Paulo Freire no planejamento e desenvolvimento de projetos educativos locais, na atualidade, em Portugal. Coimbra: Universidade de Coimbra, 2013. Disponível em: https://www.semanticscholar.org/paper/OQUE-PODEMOS-APRENDER-COM-PAULO-FREIRE-NO-E-DE-NA-

Alcoforado/dd044ba082cd57d8068dc8578e42d63312479ecc . Acesso em: 20 ago de 2019. 
ALCOFORADO, Luís. Paulo Freire na formação de especialistas em educação e formação de adultos e intervenção comunitária. Revista Interritórios, Caruaru, v. 2, n. 2, p.84-111, jul./dez., 2016.

BRANDÃO, Carlos Rodrigues. O que é o método Paulo Freire. 10 ed. São Paulo: Brasiliense, 1986.

BOURDIEU, Pierre. Practical Reason: On the Theory of Action. Stanford, CA: Stanford University Press, 1988.

BOZU, Zaia; IMBERNON, Francesc. Creando comunidades de práctica y conocimiento en la Universidad: una experiencia de trabajo entre universidades de lengua catalana. RUSC, Barcelona, v. 6, n. 1, p. 1-10, 2009. Disponível em: http://rusc.uoc.edu/ojs/index.php/rusc/ article/view/2. Acesso em: 20/06/2020.

DOS SANTOS COSTA, Graça; LESSA, Patrícia; MALLOWS, David. Paulo Freire, the decolonial curriculum and the experience of the Professional Masters in Youth and Adult Education in Bahia, Brazil. The Adult Learner 2020. Dublin: AONTAS, 2020. Disponível em https://www.aontas.com/assets/resources/Adult-Learner-Journal/ALJ\%202020/Aontas\%20 Adult\%20Learner\%20Journal\%202020.pdf. Acesso em 10/10/2020.

CABELlEIRA, Denise Mross . Comunidades de Prática: Conceitos e Reflexões para uma Estratégia de Gestão do Conhecimento. XXXI Encontro da ANPAD. Rio de Janeiro: ANPAD, 2007. Disponível em http://www.anpad.org.br/admin/pdf/ADI-B2953.pdf. Acesso em 01/07/2020.

FREIRE, Paulo. Educação como prática de liberdade. 14 ed. Rio de Janeiro: Paz e Terra, 1983.

FREIRE, Paulo. Educação de Adultos: algumas reflexões. In: GADOTTI, Moacir; ROMÃO, José Eustáquio. Educação de Jovens e Adultos: teoria, prática e proposta. 12 ed. São Paulo: Cortez, 2008, p.15-17.

FREIRE, Paulo. Ação cultural para a liberdade e outros escritos. 14 ed. Rio de Janeiro: Paz e Terra, 2011.

FREIRE, Paulo. Pedagogia da Autonomia: saberes necessários à prática educativa. 47 ed. Rio de Janeiro: Paz e Terra, 2013.

FREIRE, Paulo. Pedagogia do Oprimido. 56 ed. Rio de Janeiro: Paz e Terra, 2014.

FREIRE, Paulo. Cartas a Cristina: reflexões sobre minha vida e minha práxis. São Paulo: Paz e Terra, 2015

FREIRE, Paulo. Conscientização. São Paulo: Cortez, 2016.

GUERRA, Marcos. Sobre as 40 horas de Angicos. Em Aberto, Brasília, v. 26, n. 90, p.21-44 jul./dez., 2013. 
GROTLÜSCHEN, Anke; MALLOWS, David.; REDER, Steve.; SABATINI, John. (2016). Adults with Low Proficiency in Literacy or Numeracy. OECD Education Working Papers, Paris, n. 131, 2016.

HELLER, Agnes. O cotidiano e a história. 2 ed. São Paulo: Paz e Terra, 1985.

LAVE, Jean; WENGER, Etienne. Situated Learning: Legitimate Peripheral Participation. Cambridge, UK: Cambridge University Press, 1991.

LOUREIRO, Carlos Frederico B.; FRANCO, Jussara Botelho. Aspectos Teóricos e Metodológicos do Círculo de Cultura: uma possibilidade pedagógica e dialógica em educação ambiental. In: LOUREIRO, Carlos Frederico B.; TORRES, Juliana Rezende (Orgs). Educação Ambiental: dialogando com Paulo Freire. São Paulo: Cortez, 2014, p.155-180.

MEKSENAS, Paulo; PENTEADO, Nilda. Pastoral da juventude - setor pastoral vila prudente. São Paulo, maio de 1982. Como trabalhar com o povo? PED - 0019 - Apresentação Paulo Freire. Disponível em: https://pt.scribd.com/document/128149455/Como-TrabalharCom-o-Povo-Paulo-Freire.Acesso em: 16 jul. 2017.

PADILHA, Paulo Roberto. O "Círculo de Cultura" na perspectiva da intertransculturalidade. [S.1.], 2012. Disponível em: https://gepffaccat.files.wordpress.com /2012/10/o-cc3adrculo-de-cultura-na-persepectiva-intertransculturalidade-paulo-robertopadilha.pdf. Acesso em: 04 jun. 2017.

ROMÃO, José Eustáquio. O Círculo de Cultura em Lugar da Aula. In: ROMÃO, José Eustáquio. RODRIGUES, V. Lane. Paulo Freire e a Educação de Adultos: teoria e práticas. São Paulo: IPF; Brasília: Liber Livro, 2011, p. 57- 97.

SCOCUGLIA, Afonso Celso. A progressão do pensamento político de Paulo Freire. In: TORRES, Carlos Alberto. Paulo Freire y la agenda de la educación latinoamericana en el siglo XXI. Buenos Aires: CLACSO, 2001, p. 323-348. Disponível em:

http://bibliotecavirtual.clacso.org.ar/ar/libros/torres/scocuglia.pdf. Acesso em: abr. 2018.

SCOCUGLIA, Afonso Celso. A história das idéias de Paulo Freire e a atual crise de paradigmas. 2 ed. João Pessoa: Ed. Universitária UFPB, 1999.

SILVA, Francisco Canindé da. A pedagogia freireana da experiência de Angicos aos dias atuais. In: SAMPAIO, Marisa Narcizo; PINHEIRO, Rosa Aparecida. 40 horas de Angicos e campanha de pé no chão também se aprende a ler: movimentos e memórias de da Educação de Jovens e Adultos. São Paulo: Livraria da Física, 2014, p. 121-145 (Coleção Contextos da Ciência).

WENGER, Etienne. Communities of practice: learning, meaning, and identity. Cambridge: University Press, 1998.

WENGER, Etienne; McDERMOTT, Richard; SNYDER, William. Cultivating communities of practice: a guide to managing knowledge. Boston: Harvard Business School Press, 2002. 


\section{SOBRE OS AUTORES:}

\section{Soraia Sales Baptista da Costa Machado}

Doutoranda em Ciências da Educação na Universidade e Coimbra (UC). Coordenadora Pedagógica do Ensino Fundamental e da EJA na Secretaria Municipal do Salvador (BA). Membro do Grupos de Pesquisas Educação, Direitos Humanos e Interculturalidade (GREDHI) e Formação de Professores, Autobiografia e Políticas Públicas (FORMAP). Email: sosales21@gmail.com.

(iD https://orcid.org/0000-0002-8340-0960

\section{Graça dos Santos Costa}

Doutora em Pedagogia pela Universidade de Barcelona (UB). Professora Titular da Universidade do Estado da Bahia (UNEB) e Professora Associada da Universidade de Barcelona (UB). Líder do Grupo de Pesquisa Educação, Direitos Humanos e Interculturalidade (GREDHI) e membro do grupo de Grupo de Pesquisa e Assessoramento Didático (GIAD). E-mail: gracacosta@gmail.com

iD https://orcid.org/0000-0001-7770-0118

\section{David Mallows}

Doctor of Teacher Education. Principal Teaching Fellow at the UCL Institute of Education, London, UK. E-mail: d.mallows@ ucl.ac.uk

iD https://orcid.org/0000-0001-8378-5488

\section{Patrícia Lessa Santos Costa}

Doutora em Ciências Sociais pela Universidade Federal da Bahia (UFBA). Professora dos Mestrados Profissionais em Educação de Jovens e Adultos (MPEJA) e em Gestão e Tecnologia Aplicadas à Educação (GESTEC) do Departamento de Educação I da Universidade do Estado da Bahia (UNEB) - Brasil. E-mail: plessacosta@gmail.com (iD https://orcid.org/0000-0002-2038-8132 